\title{
FIELD DEPENDENCE-INDEPENDENCE AND BRAIN ORGANIZATION: THE CONFLUENCE OF TWO DIFFERENT WAYS OF DESCRIBING GENERAL FORMS OF COGNITIVE FUNCTIONING? A THEORETICAL REVIEW
}

\author{
Authors: Carolina Tinajero, María Fernanda Páramo, Fernando Cadaveira, \\ Socorro Rodríguez Holguín
}

This is the peer reviewed version of the following article: Tinajero, C., Páramo, M.F., Cadaveira, F. \& Rodríguez Holguín, S. (1993). Field dependence-independence and brain organization: the confluence of two different ways of describing general forms of cognitive functioning? A theoretical review. Perceptual and Motor Skills, 77(3):787-802. https://doi.org/10.2466/pms.1993.77.3.787

This article may be used for non-commercial purposes in accordance with Ammons Scientifics and SAGE Publications terms and conditions for use of selfarchived versions. 


\title{
Field dependence-independence and brain organization: the confluence of two different ways of describing general forms of cognitive functioning? A theoretical review
}

\author{
Carolina Tinajero, María Fernanda Páramo, Fernando Cadaveira, Socorro Rodríguez \\ Holguín
}

University of Santiago de Compostela

(Accepted August 3, 1993)

\section{Summary}

We reviewed a total of 67 studies of the relationship between the cognitive style dimension of field dependence-independence and brain organization. To date, such studies have followed three basic lines of approach: (1) cerebral localization of processes involved in field dependence-independence; (2) evaluation of the relationship between field dependence-independence and hemisphericity; (3) evaluation of the relationship between field dependence-independence and hemispheric differentiation. The results of all three types of study are largely coherent with the differentiation theory formulated by Witkin and his coworkers. In addition, findings to date are of interest in that they suggest new directions for more detailed investigation of the relation-ship between field dependenceindependence and brain organization. These directions appear very promising for improving our understanding of both the nature of cognitive styles and the functioning of the brain in general.

Cognitive styles have been defined as relatively stable, self-consistent modes of adaptation that mediate the ways in which individuals process information (Brodzinsky, 1982). Of the cognitive style dimensions identified to date, field dependenceindependence is that which has received most attention: Huteau (1987) suggested that this is due to the fact that field dependence-independence is manifested in the majority of psychological domains, providing a coherent and consistent reflection of individual behaviour differences. The same author (Huteau, 1982) has commented on the poten-tial for alignment of research efforts related, on the one hand, to field dependence-independence and, on the other, to neuropsychology (an approach which similarly provides a basis for describing general forms of psychological function). The points of contact between the two forms of description have generated strong interest in the relationship between field dependence-independence and brain organization.

The study of this relationship has followed two quite different approaches. The first involves attempts to identify the areas of the brain implicated in field dependenceindependence and takes its inspiration from a series of studies carried out at the beginning of this century with the aim of determining the physiological basis of perceptual selectivity (i.e., selective attention to certain aspects of perceptual information). The second approach involves examination of possible differences between extreme field-dependent and field-independent subjects with respect to the functional asymmetry of the cerebral hemispheres, giving rise to two basic questions. Firstly, do field-dependent and field-independent subjects differ in the characteristic activation patterns of their cerebral hemispheres? Secondly, do they differ in the 
degree or direction of hemispheric lateralization of specific functions? Here, considering both approaches, we detail the principal experimental and theoretical contributions to the study of the relationship between field de-pendence-independence and brain organization.

\section{Cerebral localization of field dependence-independence measures}

As mentioned above, interest in this question arose from a series of studies aimed at identifying the physiological basis for perceptual selectivity. Some of these studies focused on cerebral localization of the processes in-volved in the recognition of perceptual elements against an embedding background. The pioneers of this approach were Teuber and his coworkers (Teuber, Battersby, \& Bender, 1951; Battersby, Krieger, Pollack, \& Bender, 1953; Teuber \& Weinstein, 1956), who examined the effect of cerebral lesions on performance on Gottschaldt's test.

In the first of these studies, Teuber, et al. (1951) studied 131 World War II veterans with traumatic cerebral lesions. The subjects were divided into three groups according to the location of the damage: (a) anterior (frontal, frontotemporal, and frontoparietal), (b) intermediate (parietal, temporal, and temporoparietal), and (c) posterior (occipital, parieto-occipital and temporo-occipital). An additional control group comprised 40 veterans with no cerebral injury. The groups were compared in terms of performance on the Gottschaldt test, with scores on each of the test's five sections being consid-ered separately. On all five sections, control subjects obtained significantly higher scores than subjects with cerebral damage. Significant differences between subjects with brain damage were only observed on three sections of the test (the second, third, and fifth): on all three sections, subjects with anterior lesions scored significantly better than subjects with posterior lesions.

Battersby, et al. (1953) used the Gottschaldt test to evaluate perceptual deficit in subjects with anterior, posterior, or multiple cerebral neoplasms. Again, brain-damaged subjects scored lower than control subjects, both before and after surgical removal of the neoplasm. However, location of the neoplasm was not significantly related to performance on any of the test's five sections. Teuber and Weinstein (1956) again studied brain-damaged subjects, but for the first time they grouped subjects according to both symptomatology and the hemispheric location of the lesion. Performance on the Gottschaldt test was very similar for all subjects except aphasics, who performed less well. These authors considered that aphasia and disembedding deficiency have some intellectual feature in common, and that this feature is located in the left hemisphere. Russo and Vignola (1967) also reported that aphasics displayed greater deficits in performance on Gottschaldt's test than subjects with other symptoms and with cerebral damage to other regions. However, they found that subjects with right-hemisphere lesions performed less well than nonaphasic subjects with left-hemisphere lesions, who obtained scores similar to those of control subjects.

Tests of perception of verticality were pioneered by two groups, Bruell and Pesyczynski (1958) and Hulicka and Beckstein (1961). These workers compared performance of hemiplegics with unilateral hemispheric lesions and control subjects on the Rod and Frame Test (RFT). In both studies hemiplegic subjects performed worse than control subjects; in neither, however, were performance differences related to location of the lesion. 
It was then already apparent from early studies that field dependence-independence performance depended on processes related to both cerebral hemispheres. Later studies, however, began to suggest that some extent of hemispheric dominance was involved, in the light of general research into hemispheric specialization, and the subsequent introduction of first the verbal-nonverbal, and later the analytic-holistic, dichotomies to provide a theoretical basis for this phenomenon. The studies of Berent and his coworkers (Berent \& Silverman, 1973; Cohen, Berent, \& Silverman, 1973) were influential in this respect: these workers suggested that field dependence was the result of some subclinical cerebral injury and focused their efforts upon the localization of the putative damage. In the first of these studies (Berent \& Silverman, 1973), fielddependent and -independent subjects were presented tests considered sensitive to possible cerebral pathologies, involving verbal (word) and visual (shape) pairedassociate learning tasks. Field-dependent subjects performed worse on the learning of verbal pairs, whilst performance on the visual learning tasks was similar to that of fieldindependent subjects. This led the authors to consider that the dysfunction might be localized in the left hemisphere. Cohen, et al. (1973) tested this interpretation by com-paring Rod and Frame Test performance of psychiatric patients before and after unilateral electroconvulsive shock treatment. Subjects who received the treatment to the left hemisphere showed a decline in performance; those who received the treatment to the right hemisphere showed an improvement. In the opinion of the authors, this confirmed that field dependence is due to a left-hemisphere dysfunction, manifested as attention to information which is not relevant to task completion. The improvement in execution following treatment to the right hemisphere was attributed to a reduced response to the perceptual context. Waber (1977a) supported this hypothesis, referring as follows to the relationship between the left hemisphere and analytic processes:

.. since left hemispheric analytic functions are thought to be critical to perceptual disembedding, individuals in whom the balance of activity strongly favors the left hemisphere (... ) will show better performance at such tasks ... (p. 1084).

Pizzamiglio and Carli (1974), on the other hand, drew attention to the similarity between field dependence and certain deficits brought about by right-hemisphere lesions (such as deterioration in the perception of overlapping figures and reduced body concept). In view of these similarities the authors suggested that the right hemisphere played a dominant role in field dependence-independence; the results of their own experimental work, however, provided little firm support for this hypothesis. They compared performance of 57 patients with unilateral lesions on Thurstone's (1944) Embedded Figures Test, and on the auditory (White, 1954) and tactile (Axelrod \& Cohen, 1961) variants of this test. Significant differences in support of their hypothesis (i.e., as a function of location of lesion) were found only in the case of the tactile tests. Garrick (1978) supported Pizzamiglio and Carli's interpretation, pointing out certain similarities between field independence and functions traditionally attributed to the right hemisphere (concept formation, creativity, management of spatial information, etc.). This author also criticized the conclusions reached by Berent and his coworkers, citing studies in which verbal paired-associate tasks had been equated with imaginative processes related to the right hemisphere, thereby bringing into question their value as indicators of the hypothetical cerebral damage occurring in fielddependent subjects. Similarly, Garrick drew attention to the contradiction between Berent's results and those of other studies of verbal aptitude in field-dependent 
subjects. Berent's studies had indicated a lack of significant differences in the learning of visual pairs: Garrick pointed out that this brought into doubt the interpretation of field dependence as a cerebral deficit, and pointed out that normal field-dependent subjects perform worse on more complicated visuoperceptual tasks. Furthermore, Garrick questioned the value of the studies of unilateral electroconvulsive shock treatment on the grounds that the contralateral hemisphere might easily have been affected as well. In addition, he pointed out that the effect of the treatment on the characteristic functions of a given area could not be assumed to be inhibitory and that in some cases data suggest an excitatory effect. In Garrick's view, then, the results of Berent and his coworkers do not provide support for left-hemisphere dominance of field dependenceindependence.

Later studies in this field have not clarified the controversy. Corkin (1979) studied 74 subjects with unilateral lesions, in some cases accompanied by aphasia or hemiparesis (which Corkin took to be an indicator of the extent of the lesion). Hemiparetic patients displayed more marked deficits on the Embedded Figures Test, independently of whether the lesion was located in the left or right hemisphere and of the presence or absence of aphasia. There was also a relationship between the severity of hemiparesis and per-formance on the test. Corkin concluded that the decline in perception of embedded figures was determined more by the extent of the lesion than by its actual location.

Falcone, Smith, and Given (1980) made another attempt to assess the area of the brain implicated in field dependence-independence, starting out with a sample of normal subjects; they constructed a tachistoscopic version of the Embedded Figures Test and presented the stimuli unilaterally. They found a strong right visual-field superiority in choosing a simple figure embedded in a complex one, suggesting that the processes characteristic of the left hemisphere are advantageous to performance on this modified embedded-figures task. In a later study, however, Falcone (1985) found a negative correlation between scores on the tachistoscopic and the Group Embedded Figures Test, suggesting that the two tests do not measure the same thing and that the tachistoscopic version involves processes not required for success on the standard test.

Thus the first approach to the study of the relationship between field dependenceindependence and brain organization -that of trying to localize measures of cognitive style to specific brain regions- produced inconclusive results. In fact, these studies suggest that this dimension of cognitive style involves complex tasks demanding the participation of various areas and systems of the brain. The most recent theoretical formulations refer to a "conflict" between alternative contralateral strategies which are balanced by control processes localized to the frontal lobes: it is through this modulation that individual behaviour differences are manifested, with results that may be more or less appropriate to the task in hand. Thus, Pascual-Leone (1989) stated:

Field Dependence-Independence appears ( ... ) as a dynamic balance of the brain's functional structures in situations where both hemispheres enter into a cognitive conflict; and two silent functions of the prefrontal lobes, the M-capacity and the l-interruption, play the decisive role-mediated by executive schemes ( $E-$ factor) generally stored in the prefrontal lobes (p. 66).

Globerson (1989) supported this interpretation in a review of various studies which provide evidence for a regulatory role of the frontal lobes. She discussed the apparent 
affinities between these frontally located regulatory processes and manifestations of field dependence-independence.

\section{Field dependence-independence and hemisphericity}

Hemisphericity can be defined as an individual tendency towards preferential use of the processes associated with one or the other cerebral hemisphere (Bradshaw \& Nettleton, 1981; Hellige, 1990; Minagawa \& Kashu, 1989). The formulation of the construct can be traced to Bakan (1971) who proposed the use of lateral eye movements as an indicator of hemispheric activation. According to this author, righthemispheric activity leads to eye movement to the left, and vice-versa. In experimental studies he found that lateral eye movements were affected by type of task as might be predicted on the basis of current theories of hemispheric specialization: verbal tasks were associated with lateral eye movements largely to the right, whilst spatial tasks were associated with movements largely to the left. The same author also demonstrated the existence of stable patterns of differences between individuals with respect to preferential activation of one or the other hemisphere. These patterns were associated with other dimensions of individual difference: some of them, such as vocational preference or defense mechanisms, suggested a correspondence between an individual's characteristic direction of lateral eye movements and field dependenceindependence, and further studies were carried out with the aim of confirming this possibility. In the majority of these studies (Barnat, 1974; De Witt \& Averill, 1976; Hoffman \& Kagan, 1977; Schroeder, Eliot, Greenfield, \& Soeken, 1976; Shevrin, Smokler, \& Wolf, 1979), Embedded Figures Test performance of subjects with lateral eye movements predominantly to the right ("right movers") was compared with that of subjects with eye movements predominantly to the left ("left movers"). Contrary to expectations, hemisphericity-related differences in cognitive style were not observed. Parallel studies gave no significant differences in perception of verticality between "left movers" and "right movers" (Pierro \& Goldberger, 1982; Shevrin, et al., 1979).

In another two studies different measures of hemisphericity were used, and in both cases a significant relationship with field dependence-independence was reported. Semple, Oltman, and Goldstein (1979) recorded electro-encephalograms of fielddependent and -independent subjects grouped on the basis of the Embedded Figures Test and the Rod and Frame Test. They compared characteristics of the recording between hemispheres, both at rest and during the execution of various simple tasks (arithmetic, and recognition of faces, words, and moving abstract shapes). Fieldindependent subjects displayed greater activation of the right hemisphere than fielddependent subjects under all recording conditions. Similarly, Beer (1988) used the "Your Style of Thinking and Learning" test to evaluate hemisphericity. This instrument contains questions about the subject's favourite activities and about their performance on tasks characteristic of each cerebral hemisphere. Subjects inferred to have righthemisphere dominance performed significantly better on the Embedded Figures Test.

In general, while there appears to be a relation between field dependenceindependence and hemisphericity, it is by no means straightforward. In some studies, field-independent subjects have shown a tendency towards preferential use of the right hemisphere, whilst field-dependent subjects have not shown any clear tendency. Some authors have suggested that the preferential use of one hemisphere for a certain task will eventually lead to better performance with that hemisphere on that task (Gordon, 
1989; Shedletsky, 1990). Indeed, field-independent subjects are characterized by greater visuo-perceptive aptitude than field-dependent subjects (Goodenough, Oltman, \& Cox, 1987), and this might be due to a tendency to use processes localized to the right hemisphere.

\section{Field dependence-independence and hemispheric differentiation}

The enormous quantities of data generated by early studies led Witkin and his coworkers to propose a suitable theoretical model: the differentiation theory of Witkin, Dyk, Paterson, Goodenough, and Karp (1962), which is based on the assumption that an organism tends during its development towards a greater structural complexity, functional specialization, and autonomy with respect to the environment. In a parallel manner, the concept of differentiation was adopted in neurophysiology to refer, amongst other processes, to the progressive specialization of different parts of the brain for different functions during development, and to the establishment of peripheral dominance (Palmer, 1974; Reuchlin, 1987). A query arose as to the existence of correspondence between psychological and neurophysiological differentiation. In the second version of their theory, in view of early results in favour of such a correspondence, Witkin and his coworkers incorporated neurophysiological segregation (manifested as hemispheric specialization) as an indicator of differentiation. Since that time, numerous studies have been carried out with the aim of verifying and further exploring the relationship between psychological and neurophysiological differentiation. In what follows we will analyse the principal findings to date in this line of research. We will consider firstly those studies which have looked at the relationship between field dependence-independence and peripheral dominance and secondly at studies of the lateralization of functions principally associated with one of the cerebral hemispheres.

\section{Field Dependence-Independence and Peripheral Dominance}

Peripheral dominance, and particularly handedness, is considered an indicator of hemispheric specialization due to the systematic association which is apparent between the two dimensions. Hellige (1990), for example, presented data on speech lateralization in right- and left-handed subjects: $95 \%$ of right-handed subjects displayed left-hemisphere dominance for speech and $5 \%$ displayed right-hemisphere dominance, whilst in the case of left-handed subjects, $62 \%$ displayed left-hemisphere dominance, $19 \%$ displayed right-hemisphere dominance, and $19 \%$ displayed bilateral representation. On the other hand, handedness has been associated with the degree of hemispheric specialization (Palmer, 1974). The correspondence between field dependence-independence and peripheral dominance may therefore provide a first approximation to the relationship between the former and hemispheric differentia-tion. Witkin, Lewis, Hertzman, Machover, Meissner, and Wapner (1954) were the first to publish data in this connection, reporting greater field de-pendence amongst the lefthanded subjects of their sample. Similarly, in the sensory isolation study of Culver, Cohen, Silverman, and Shmavonian (1964), the authors found that, of the 24 subjects in their sample, those who displayed greatest field dependence were left-handed. However, the results of later studies have been less clearcut. So whilst both Silverman, Adevai, and McGough (1966) and Berent and Silverman (1973) reported greater field de-pendence amongst left-handed subjects when field dependence-independence was 
measured using the Rod and Frame Test, the former authors reported no significant differences when the Embedded Figures Test was used. In a more recent study, Newland (1984) obtained contradictory results on application of the Group Embedded Figures Test: left-handed subjects scored higher on this test than right-handed subjects. This apparent contradiction may be due to differences in the two ways of measuring field dependence-independence. On the other hand, as Palmer (1974) points out, it might also be due to laterality being less well-established amongst lefthanded subjects, which would modulate the relationship with field dependenceindependence. This latter interpretation seems to have been confirmed by studies which have controlled for this possibility from one of two viewpoints, the coherence be-tween hand and eye dominance and the extent of dominance in each case.

Amongst the first group of studies those of Dawson $(1972,1977)$ are noteworthy: this author found greater field dependence for adults with coherent laterality than for those who displayed differences between hand and eye dominance. Roszkowski and Snelbecker (1987), on the other hand, found that field dependence-independence was not dependent on the coherence of hand and eye dominance in 8-year-old children; however, laterality was quite probably not fully established in many of these children, which clearly affects interpretation of their results. Studies in the second group have been more consistent: whether hand, eye, or foot dominance has been considered, a clear relationship between the degree of laterality and field dependence-independence has been apparent, with field-independent subjects tending to display greater laterality (Oltman \& Capobianco, 1967; Palmer, 1974; Pizzamiglio, 1974). Of particular interest is the work of Palmer (1974), who examined the possible influence of method used to measure handedness on interpretation of relationships between this characteristic and cognitive styles. Most studies involving determination of handedness have used questionnaires or simple criteria such as the writing hand or the hand used to catch an object thrown by the experimenter. Palmer used a questionnaire about the hand used for various everyday tasks and a series of 19 tests to evaluate the performance of each hand in terms of a range of indices ineluding strength and precision. Cognitive style was found to be associated with degree of peripheral dominance regardless of the assessment method used.

\section{Field Dependence-Independence and Lateralization of Cognitive Processes}

The biggest problem affecting research in this field is the choice of test to measure lateralization. Frequent use is made of subjects with cerebral lesions, commissurotomized subjects, or subjects who have received injections of sodium amital in the carotid. Mishkin and Forgays (1952) and Kimura (1961) introduced the socalled behavioural techniques which have been widely used in studies of field dependence-independence and hemispheric differentiation: these techniques consist basically of simple tasks destined to be handled by one or the other cerebral hemisphere. The stimuli on which the tasks are based are supplied unilaterally, such that it is then possible to compare the performance of subjects according to whether the stimuli were received by the right or left hemisphere. Increasing differences between performances are then inferred to indicate increasing hemispheric specialization of the task in question, and vice-versa. Studies of this type have compared between-hemisphere performance differences of extreme field-dependent and -independent subjects. A note of caution is called for at this stage. If the performance of a given subject on a given laterality task differs according to the hemisphere receiving the stimulus, this may be taken as evidence that the skill in question is in some way more closely associated with one hemisphere, but not as 
evidence that the skill is mediated exclusively by that hemisphere or that the observed lateralization is a reflection of structural differences between hemispheres. This distinction has been stated clearly by Bradshaw and Nettleton (1981, 1983), who proposed a "quantitative-relative" approach to hemispheric asymmetry, stressing that it should be viewed as a relative rather than an absolute phenomenon.

In the case of left-hemisphere studies, verbal stimuli have been used, in some cases in dichotic listening tasks and in other cases in tachistoscopic visual mode. Listening tasks have been more frequently used, and have generally indicated that fieldindependent subjects display greater hemispheric differentiation in recognition and repetition of digits (Fernandez-Ballesteros \& Manning, 1985; Pizzamiglio, 1974; Zoccolotti, 1977), syllables (Waber, 1976, 19776), and words (Fernandez-Ballesteros \& Manning, 1985; Longoni, Zoccolotti, \& Speranza, 1980). Mohr's (1987) results likewise suggested greater differentiation of field-independent subjects, but the relationship was not statistically significant. Of particular interest in this connection is Bloom-Feshbach's (1980) observation that field-independent subjects not only dis-play more marked lefthemisphere dominance in syllable recall tasks, but that they also perform better with their right hemisphere on such tasks than field-dependent subjects. In the opinion of the author, this provides evidence of greater between-hemisphere integration in fieldindependent subjects. Visual mode studies of this type, which have generally involved letter recogni-tion and repetition, again indicate that field-independent subjects display greater hemispheric specialization (Manning \& Fernandez-Ballesteros, 1982; Zoccolotti, 1977; Zoccolotti \& Oltman, 1978). Zoccolotti (1977) also used tapping interference to evaluate lateralization; specifically, he asked his subjects to read a text whilst at the same time tapping the tabletop with each of their fingers in sequence, using the left or right hand. When the right hand was used, the interference of the tapping task in the reading task was more marked for field-independent subjects than in field-dependent subjects, again suggesting greater hemispheric specialization of the former.

A variety of tasks -the most popular involving the recognition of tachistoscopically projected unfamiliar faces- have been used to study the extent of lateralization of righthemisphere-associated functions. Most authors have reported that field-dependent and -independent subjects display opposing tendencies: the former perform better when the task stimuli are addressed to the left hemisphere, and the latter when the stimuli are addressed to the right hemisphere (Pizzamiglio \& Zoccolotti, 1981; Pizzamiglio, Zoccolotti, Mammucari, \& Cesaroni, 1983; Rapaczynski \& Ehrlichman, 1979; Zoccolot-ti, 1977; Zoccolotti \& Oltman, 1978). This tendency is, however, less marked amongst field-dependent subjects, again supporting the hypothesis of less marked hemispheric specialization of these subjects.

Various authors have suggested that the opposite lateralizations observed in fielddependent and -independent subjects may be due to a tendency for subjects to use different strategies for task solving (Langoni, et al., 1980; Zoccolotti \& Pizzamiglio, 1986). Only one study (Proudfoot, 1983), however, has tested this hypothesis. This author gave his subjects a facial recognition test in two stages. Presented unfamiliar faces, subjects were asked to make first "social" and then "physical" judgements. In general, the "social" judgement was left-hemisphere dominated and the "physical" judgement was right-hemisphere dominated; this pattern was also displayed by fieldindependent subjects, whilst field-dependent subjects did not display significant between-hemisphere differences on either type of judgement. The results of this study are not therefore conclusive, and it deserves to be repeated with the inclusion of 
different procedures, perhaps more closely suited to the differences in strategy displayed as a function of cognitive style.

Finally, the facial perception studies of Oltman, Ehrlichman, and Cox (1977) should be mentioned. These authors did not use tachistoscopic presentation, but instead a task designed by Gilbert and Bakan (1973) consisting of the presentation of one face on the upper half of a sheet and of two more faces on the lower half, one made up of the right half of the first face and its mirror image, the other of the left half of the first face and its mirror image. Subjects were then asked to decide which of the two faces on the lower half most closely resembled the face on the upper half. According to the authors, the face comprised of the two right halves -that is, of the side of the original face falling on the observer's left visual field, which projects more directly to the right hemisphere- is more frequently chosen, suggesting right-hemisphere dominance in facial recognition. A similar tendency has been reported in numerous studies of facial perception (Bradshaw \& Net-tleton, 1981) and, in a study by Oltman, et al. (1977), was observed in field-independent but not field-dependent subjects.

Another process associated with the right hemisphere which has been the subject of considerable interest is shape perception. Studies have used both tachistoscopic presentation of visual stimuli and tactile stimuli. In the former, as with facial recognition, field-dependent and -independent subjects have shown opposing tendencies (Falcone, 1985; Hannay, 1976). Falcone's study is of particular interest since the figures from the Embedded Figures Test were projected tachistoscopically. Only in the study of Manning and Fernandez-Ballasteros (1985) was a similar effect observed using tactile stimuli; all others studies using tasks of this type have indicated that the left hand (right hemisphere) is dominant in field-independent subjects and that neither hand (hemisphere) is dominant in field-dependent subjects (Weener \& Van Blerkom, 1982; Zoccolotti, Passafiume, \& Pizzamiglio, 1979). Van Blerkom (1987) controlled for the sex of subjects: female field-independent subjects did not display significant betweenhemisphere differences in performance on a tactile shape-recognition task.

Similarly, neither line nor point perception have displayed opposing lateralization as a function of field dependence-independence. In the case of line perception, Fallik and Eliot (1985) showed no significant relationship between field dependenceindependence and extent of hemispheric specialization. In the case of point perception, Fernandez-Ballesteros and Manning (1981) observed greater specialization for fieldindependent subjects.

The results of research into hemispheric specialization for the management of musical information have tended to vary according to both task characteristics and individual differences such as musical experience (Bradshaw \& Nettleton, 1981). The relationship of this area with differences in cognitive style is thus of particular interest. However, only two studies have looked at this relationship. Fernandez-Ballesteros and Manning (1985) observed greater hemispheric specialization in field-independent subjects than in field-dependent subjects on a dichotic listening task involving tune recognition. The results of Burton, Morton, and Abbess (1989) are more complex. These authors asked their subjects to estimate the number of notes in a chord received by one ear; subjects were allocated to one of three groups according to heir musical experience (no experience, music students, and music professionals). Both subjects with no musical experience and music students displayed right-hemisphere dominance on this task, although this was less marked in the music students. Music professionals displayed left-hemisphere dominance. There was no significant relationship between field 
dependence-independence and extent of lateralization in subjects with no musical experience; in music students and music professionals there was a significant relationship. In the opinion of the authors this indicates a relationship between lateralization tendencies and the strategies preferentially employed by subjects. Greater musical experience suggests a more analytic approach to the management of musical information and, accordingly, a greater left-hemisphere involvement. This type of analytic strategy is similar to those strate-gies which are typically used by fieldindependent subjects.

To conclude this final section which has dealt with the relationship between field dependence-independence and hemispheric differentiation, we should mention two studies in which the authors have measured jointly lateralization to both hemispheres. These studies have been based upon EEG recording whilst the subject carries out simple mathematical, spatial, or verbal tasks. O'Connor and Shaw (1977) used the coherence between different pairs of epochs recorded from both hemispheres. Fielddependent subjects displayed greater between-hemisphere coherence suggesting, in the authors' opinion, that hemispheric differentiation was less marked. Oltman, Semple, and Goldstein (1979) looked at between-hemisphere correlations between peak amplitudes in field-dependent and -independent subjects. The former displayed stronger correlations on all the tasks considered by these authors. Finally, the reader will have noted that, in our discussion of studies on lateralization of cognitive processes, we have not specified the types of test used to measure field dependenceindependence. This is because the tendencies emerging from work in this field appear to be independent of the test used.

\section{Conclusions}

The research carried out to date on the relationship between field dependenceindependence and cerebral function suggests that the differences between field dependence and independence are more than just general deficiencies in, or preferences for, mechanisms based in one or other of the hemispheres. The data available are generally in agreement with the differentiation theory put forward by Witkin and his coworkers (Witkin, et al., 1962; Witkin, Goodenough, \& Oltman, 1979), in that hemispheric specialization is consistently greater for field-independent subjects than for field-dependent subjects. On the other hand, various interesting directions for future research are apparent. One particularly promising direction, as remarked by Zoccolotti and Pizzamiglio (1986), is that aimed at unravelling the relationship between the way subjects with different cognitive styles manage information, and individual differences in the direction or extent of lateralization of specific cognitive strategies. Research efforts along these lines should provide data of value for improving our understanding both of the nature of cognitive styles and of cerebral function in general.

The introduction of sophisticated techniques for the monitoring of cerebral activity, such as Event-related potential (ERP) recording, Positron emission tomography (PET), and Magnetoencephalography (MEG) (Gevins \& Remond, 1987) opens up a wide range of possibilities for investigation of the relationship between field dependenceindependence and brain function, whether in the context of lateralization or otherwise. Already there have been reports which suggest the existence of differences between the ERPs of extreme field-dependent and -independent subjects (Federico, 1984; 
Kapahi, 1987); these studies appear to represent just the first faltering steps along a path which holds out the promise of rich research rewards.

Finally, one particular failing has been evident in the majority of the studies reviewed here. In general, little attention has been paid to the possible role of sex in moderating of the field dependence-independence and brain functioning relationship. Men and women differ on both variables (Dawson, 1981; Hannay, 1976; Paramo, 1988), so it seems probable that they differ in the way the two variables interact.

\section{References}

AXELROD, S., \& COHEN, C. (1961) Senescence and embedded figure performance in vision and touch. Perceptual and Motor Skills, 12, 283-288.

BAKAN, P. (1971) The eyes have it. Psychology Today, 4(7), 64-67.

BARNAT, M. (1974) Some personality correlates of the conjugate lateral eye movement phenomenon. Journal of Personality Assessment, 38, 223-225.

BATTERSBY, W. S., KRIEGER, H. P., POLLACK, M., \& BENDER, M. B. (1953) Figure-ground discrimination in the "abstract attitude" in patients with cerebral neoplasms. Archives of Neurology and Psychiatry, 70, 703-712.

BEER, J. (1988) Hemispheric dominance inferred from your style of learning and thinking on reports of Necker cube reversals and maze learning. Perceptual and Motor Skills, 66, 887-890.

BERENT, S., \& SILVERMAN, A. J. (1973) Field dependence and differences between visual and verbal learning tasks. Perceptual and Motor Skills, 36, 1327-1330.

BLOOM-FESHBACH, J. (1980) Differentiation: field dependence, spatial ability and hemispheric specialization. Journal of Personality, 48, 135-148.

BRADSHAW, J. L., \& NETTLETON, N. C. (1981) The nature of hemispheric specialization in man. Behavioral and Brain Sciences, 4, 51-91.

BRADSHAW, J. L., \& NETTLETON, N. C. (1983) Human cerebral asymmetry. Englewood Cliffs, NJ: Prentice-Hall.

BRODZINSKY, D. M. (1982) Relationship between cognitive style and cognitive development: a 2-year longitudinal study. Developmental Psychology, 18, 617-626.

BRUELL, H. H., \& PESYCZYNSKI, M. (1958) Perception of verticality in hemiplegic patients in relation to rehabilitation. Clinical Orthopedics, 12, 124-130.

BURTON, A., MORTON, N., \& ABBESS, S. (1989) Mode of processing and hemisphere differences in the judgement of musical stimuli. British Journal of Psychology, 80, 169-180.

COHEN, B. D., BERENT, S., \& SILVERMAN, A. J. (1973) Field dependence and lateralization of function in the human brain. Archives of General Psychiatry, 28, 165167. 
CORKIN, S. (1979) Hidden-figures-test performance: lasting effects of unilateral penetrating head injury and transient effects of bilateral cinguloctomy. Neuropsychologia, 17, 585-605.

CULVER, C. M., COHEN, S. I., SILVERMAN, A. J., \& SHMAVONIAN, B. M. (1964) Cognitive structuring, field dependence-independence, and the psychophysiological response to perceptual isolation. In J. Wortis (Ed.), Recent advances in biological psychiatry VI. New York: Plenum. Pp. 119-128.

DAWSON, G. D. (1981) Sex differences in dichaptic processing. Perceptual and Motor Skills, 53, 935-944.

DAWSON, J. L. M. (1972) Temne-Arunta hand-eye dominance and cognitive style. International Journal of Psychology, 7, 219-233.

DAWSON, J. L. M. (1977) Alaskan Eskimo hand, eye, auditory dominance and cognitive style. Psychologia, 20, 121-135.

DE WITT, G. W., \& AVERILL, J. R. (1976) Lateral eye movements, hypnotic susceptibility and field independence-dependence. Perceptual and Motor Skills, 43, 1179-1184.

FALCONE, D. J. (1985) Laterality and field dependence. Perceptual and Motor Skills, 61, 651-657.

FALCONE, D.]., SMITH, A., \& GIVEN, T. (1980) Hemispheric laterality and field independence. Paper presented at the meeting of the Eastern Psychological Association.

FALLIK, B., \& ELLIOT, J. (1985) Intuition, cognitive style, and hemispheric processing. Perceptual and Motor Skills, 60, 683-697.

FEDERICO, P A. (1984) Event-related potential (ERP) correlates of cognitive styles, abilities and aptitudes. Personality and Individual Differences, 5, 575-585.

FERNANDEZ-BALLESTEROS, R., \& MANNING, L. (1981) Dependenciaindependencia de campo y diferenciación hemisferica: I. Asimetrla derecha en una tarea de localización espacial. Revista de Psicología General y Aplicada, 36, 385-392.

FERNANDEZ-BALLESTEROS, R., \& MANNING, L. (1985) Dependenciaindependencia de campo y diferenciación hemisferica en tareas de escucha dicótica. Estudios de Psicología, 23/24, 21-28.

GARRICK, C. (1978) Field dependence and hemispheric specialization. Perceptual and Motor Skills, 47, 631-639.

GEVINS, A. S., \& REMOND, A. (1987) Methods of analysis of brain electrical and magnetic signals. Amsterdam: Elsevier.

GILBERT, C., \& BAKAN, P (1973) Visual asymmetry in perception of faces. Neuropsychologia, 11, 355-362.

GLOBERSON, T. (1989) What is the relationship between cognitive style and cognitive development. In T. Globerson \& T. Zelniker (Eds.), Cognitive style and cognitive development. Norwood, NJ: Ablex. Pp. 71-85. 
GOODENOUGH, D. R., OLTMAN, P K., \& Cox, P. W. (1987) The nature of individual differences in field dependence. Journal of Research in Personality, 21, 81-99.

GORDON, H. W. (1989) Hemisphericity and its validity for education, vocation, and cognitive style. International Journal of Neuroscience, 47, 47-55.

HANNAY, H. J. (1976) Real or imagined lateralization of function in females? Perception \& Psychophysics, 19, 349-352.

HELLIGE, J. B. (1990) Hemispheric asymmetry. Annual Review of Psychology, 41, 5580.

HOFFMAN, C., \& KAGAN, S. (1977) Lateral eye movement and field dependenceindependence. Perceptual and Motor Skills, 45, 767-778.

HULICKKA, J. M., \& BECKSTEIN, L. (1961) Perception of vertical by hemiplegic patients. American Journal of Physical Medicine, 40, 192-200.

HUTEAU, M. (1982) Specialisation hemispherique et dependance-independance du champ. Cahiers de Psychologie Cognitive, 2, 217-222.

HUTEAU, M. (1987) Style cognitive et personnalite: La dependance-independance a l'egard du champ. Lille, France: Presses Universitaires de France.

KAPAHI, R. M. (1987) Cognitive style and anxiety as related to the P300 component of the event related potential waveform in eleven- and twelve-year-old males. Unpublished doctoral dissertation, Ohio State Univer.

KIMURA, D. (1961) Some effects of temporal lobe damage on auditory perception. Canadian Journal of Psychology, 15, 156-165.

LONGONI, A. M., ZOCCOLOTTI, P, \& SPERANZA, T. (1980) Coding strategies and laterality effects, a replication of a Seamon and Gazzaniga study (1973). Archivo di Psichologia, Neurologia e Psichiatria, 41, 479-481.

MANNING, L., \& FERNANDEZ-BALLESTEROS, R. (1982) Dependenciaindependencia de campo y diferenciación hemisferica: II. Asimetría izquierda en una tarea de reproducción de letras. Revista de Psicología General y Aplicada, 37, 637646.

MANNING, L., \& FERNANDEZ-BALLESTEROS, R. (1985) Tactile perceptual task and field dependence-independence. Perceptual and Motor Skills, 61, 503-506.

MINAGAWA, N., \& KASHU, K. (1989) Influence of cognitive style and interstimulus interval on the hemispheric processing of tactile stimuli. Perceptual and Motor Skills, $68,1031-1039$.

MISHKIN, M., \& FORGAYS, D. G. (1952) Word recognition as a function of retinal locus. Journal of Experimental Psychology, 43, 43-48.

MOHR, E. (1987) Cognitive style and order of recall effects in dichotic listening. Cortex, 23, 223-236.

NEWLAND, G. A. (1984) Left-handedness and field-independence. Neuropsychologia, 22, 617-619. 
O'CONNOR, K., \& SHAW, J. C. (1977) Field dependence, laterality and EEG. Biological Psychology, 6, 93-109.

OLTMAN, P K., \& CAPOBIANCO, F. (1967) Field dependence and eye dominance. Perceptual and Motor Skills, 25, 645-646.

OLTMAN, P K., EHRLICIIMAN, H., \& Cox, P W. (1977) Field independence and laterality in the perception of faces. Perceptual and Motor Skills, 45, 255-260.

OLTMAN, P K., SEMPLE, C., \& GOLDSTEIN, L. (1979) Cognitive style and interhemispheric differentiation in EEG. Neuropsychologia, 17, 699-702.

PALMER, R. M. (1974) Dimensions of differentiation in handedness. Journal of Clinical Psychology, 30, 545-552.

PÁRAMO, M. F. (1988) Estilo cognitivo Dependencia-Independencia de Campo y estructuración del medio ambiente familiar. Unpublished doctoral dissertation, Univer. of Santiago de Compostela, Spain.

PASCUAL-LEONE, J. (1989) An organismic process model of Witkin's field dependence-independence. In T. Globerson \& T. Zelniker (Eds.), Cognitive style and cognitive development. Norwood, NJ: Ablex. Pp. 36-70.

PIERRO, R. A., \& GOLDBERGER, L. (1982) Lateral eye-movements, field dependence and denial. Perceptual and Motor Skills, 55, 371-378.

PIZZAMIGLIO, L. (1974) Handedness, ear-preference, and field dependence. Perceptual and Motor Skills, 38, 700-702.

PIZZAMIGLIO, L., \& CARLI, R. (1974) Visual, tactile and acoustic embedded figures test in patients with unilateral brain damage. Cortex, 10, 238-247.

PIZZAMIGLIO, L., \& ZOCCOLOTTI, P (1981) Sex and cognitive influence on visual hemifield superiority for face and letter recognition. Cortex, 17, 215-226.

PIZZAMIGLIO, L., ZOCCOLOTTI, P, MAMMUCARI, A., \& CESARONI, R. (1983) The independence of face identity and facial expression recognition mechanisms: relationship to sex and cognitive styles. Brain and Cognition, 2, 176-188.

PROUDFOOT, R. E. (1983) Hemispheric asymmetry for face recognition: cognitive style and the "crossover" effect. Cortex, 19, 31-41.

RAPACZYNSKI, W., \& EHRLICHMAN, H. (1979) Opposite visual hemifield superiorities in face recognition as a function of cognitive style. Neuropsychologia, 17, 645-652.

REUCHLIN, M. (1987) Differentiation, integration hierarchique, genese. Bulletin de Psychologie, 40, 703-722.

RoszKOWSKI, M. ]., \& SNELBECKER, G. E. (1987) Peripheral laterality, field independence, and academic achievement: a reexamination of their interrelationship. Developmental Neuropsychology, 3, 53-65.

Russo, M., \& VIGNOLO, L. A. (1967) Visual figure-ground discrimination in patients with unilateral cerebral disease. Cortex, 3, 113-127. 
SCHROEDER, N., ELIOT, J., GREENFIELD, S., \& SOEKEN, K. (1976) Consistency of lateral eye shift related to preschoolers' performance on an analytical perceptual task. Perceptual and Motor Skills, 42, 634.

SEMPLE, C. M., OLTMAN, P. K., \& GOLDSTEIN, L. (1979) EEG amplitude asymmetry related to the field-dependence-independence cognitive style. Research Report, Educational Test-ing Service, Princeton, NJ.

SHEDLETSKY, L. J. (1990) Cognitive style, family handedness, and degree of laterality account for inconsistent sex differences in direction of gaze. Journal of Social Behavior and Personality, 5, 403-431.

SHEVRIN, H., SM OKLER, O. A., \& WoLF, E. (1979) Field independence, lateralization and defensive style. Perceptual and Motor Skills, 49, 195-202.

SILVERMAN, A. J., ADEVAI, G., \& McGOUGH, W. E. (1966) Some relationships between handedness and perception. Journal of Psychosomatic Research, 10, 151158.

TEUBER, H-L., BATTERSBY, W. S., \& BENDER, M. B. (1951) Performance of complex visual tasks after cerebral lesions. Journal of Nervous and Mental Disease, 114, 413-429.

TEUBER, H-L., \& WEINSTEIN, S. (1956) Ability to discover hidden figures after cerebral lesions. Archives of Neurology and Psychiatry, 76, 369-379.

THURSTONE, L. L. (1944) Factorial study of perception. Chicago, IL: Univer. of Chicago Press.

VAN BLERKOM, M. L. (1987) Haptic lateralization, field dependence, and sex. Perceptual and Motor Skills, 64, 907-914.

WABER, D. P. (1976) Sex differences in cognition: a function of maturation rate? Science, 192, 572-574.

WABER, D. P. (1977a) Biological substrates of field dependence: implications of sex differences. Psychological Bulletin, 84, 1076-1087.

WABER, D. P. (19776) Sex differences in mental abilities, hemispheric lateralization, and rate of physical growth at adolescence. Developmental Psychology, 13, 29-38.

WEENER, P., \& VAN BLERKOM , M. (1982) Dichhaptic laterality and field dependence. Brain and Cognition, 1, 323-330.

WHITE, B. W. (1954) Visual auditory closure. Journal of Experimental Psychology, 48, 234-240.

WITKIN, H. A., DYK, R. B., PATERSON, H. F., GOODENOUGH, D. R., \& KARP, S. A. (1962) Psychological differentiation. New York: Wiley.

WITKIN, H. A., GooDENOUGH, D. R., \& OLTMAN, P. K. (1979) Psychological differentiation: current status. Journal of Personality and Social Psychology, 37, 11271145.

WITKIN, H. A., LEWIS, H. B., HERTZ MAN, M., MACHOVER, S., MEISSNER, P. B., \& WAPNER, S. (1954) Personality through perception. New York: Harper. 
ZOCCOLOTTI, P. (1977) Field dependence and patterns of cerebral lateralization. Paper presented at the 48th meeting of the Eastern Psychological Association, Boston, Massachusetts.

ZOCCOLOTTI, P., \& OLTMAN, P. K. (1978) Field dependence and lateralization of verbal and configurational processing. Cortex, 14, 155-168.

ZOCCOLOTTI, P., PASSAFIUME, D., \& PIZZAMIGLIO, L. (1979) Hemispheric superiorities on a unilateral tactile test: relationship to cognitive dimensions. Perceptual and Motor Skills, 49, 735-742.

ZOCCOLOTTI, P., \& PIZZAMIGLIO, L. (1986) Lateral differences in face processing: effects of sex and cognitive style. In R. Bruyer (Ed.), The neuropsychology of face perception and facial expression. Hillsdale, NJ: Erlbaum. Pp. 201-218. 